\title{
An unusual complication after chordal sparing mitral valve replacement
}

\author{
Dusko G. Nezic, MD, PhD, FETCS, Milan M. Vukovic, MD, Milan V. Cirkovic, MD, \\ Aleksandar M. Knezevic, MD, BCh, Miomir Dj. Jovic, MD, PhD, and Miroslav M. \\ Jakovljevic, MD, FETCS, Belgrade, Serbia and Montenegro
}

\section{Clinical Summary}

A 44-year-old man with cardiac failure was admitted to our clinic for increasing dyspnea. Transesophageal echocardiography showed severe mitral regurgitation with a prolapse of the anterior leaflet. Aortic regurgitation was referred to as mild. End-diastolic diameter was $73 \mathrm{~mm}$, end-systolic diameter was $47 \mathrm{~mm}$, and ejection fraction was calculated to be 0.50 . Catheterization revealed normal coronary arteries. At the time of the operation, annular calcifications and redundant bulky leaflets contraindicated valvular repair. A bileaflet mechanical prosthesis $(31 / 33 \mathrm{~mm})$ was implanted by using Miki's mitral valve replacement (MVR) technique. Complete preservation of the whole native mitral apparatus during surgical intervention is easily accomplished with Miki's MVR technique. ${ }^{1}$ The anterior mitral leaflet is divided (the central portion is excised) into anterior and posterior segments. The divided segments are shifted and reattached to the mitral ring of the respective commissural areas (while the posterior mitral leaflet is completely preserved), and the prosthetic valve is implanted. Everting interrupted mattress stitches with pledgets placed above the annulus in the atrium were used. Every stitch passed through the annulus, then the remnant of the anterior leaflet (or through posterior leaflet), and then through the outer half of the sewing ring of the prosthetic valve. Practically, we can figure this technique as an intravalvular implantation of the prosthetic valve.

The early postoperative course was uneventful, and predischarge transthoracic echocardiography (TTE), as well as transesophageal echocardiography, showed a normal functioning mitral prosthesis, mild aortic regurgitation, and preserved ventricular function.

At regular check-up, 1 month later, TTE showed a mysterious formation (about $34 \mathrm{~mm}$ in length) attached to the posterior papillary muscle floating in the left ventricle (Figures 1 and 2).

Being afraid of possible thrombosis, dislocation, and embolization or poppet entrapments, we have urged redo surgery. To simplify the reoperation, we used a limited approach through an aortotomy across the native aortic valve, which provided excellent access to the mitral prosthesis and the left ventricular cavity. The

From the Department of Cardiac Surgery, Dedinje Cardiovascular Institute, Belgrade, Serbia and Montenegro.

Received for publication Sept 8, 2003; revisions accepted Sept 25, 2003.

Address for reprints: Dusko Nezic, MD, PhD, FETCS, Department of Cardiac Surgery, Dedinje Cardiovascular Institute, M. Tepića 1, 11040 Belgrade, Serbia and Monte Negro (E-mail: nezic@EUnet.yu).

J Thorac Cardiovasc Surg 2004;127:599-600

$0022-5223 / \$ 30.00$

Copyright (C) 2004 by The American Association for Thoracic Surgery

doi:10.1016/j.jtcvs.2003.09.044 mysterious formation appeared to be a torn (a few millimeters below the sewing line) preserved part of the anterior leaflet (reattached to the corresponding part of the posteromedial commissure at the

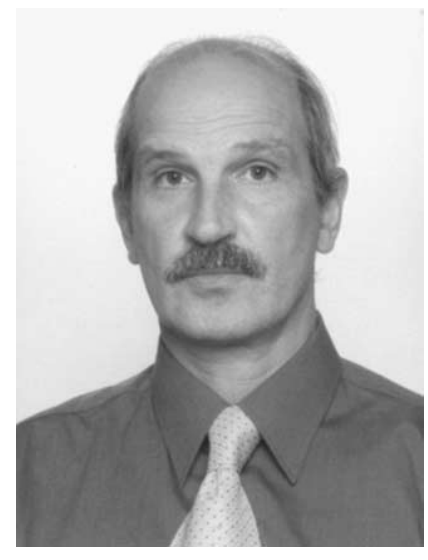
time of the first operation) still connected with chordae to the posterior papillary muscle. This remnant was cut up to the papillary muscle head, as well as the other part of the preserved anterior leaflet (reattached to the corresponding part of anterolateral commissure), which started to tear a few millimeters below the line of reattachment. Although aortic regurgitation has been estimated as mild to moderate, we have also done aortic valve replacement with a bileaflet mechanical prosthesis $(25 \mathrm{~mm})$.

The postoperative course was uneventful, and predischarge TTE showed normal functioning of the mitral and aortic prostheses together with preserved ventricular function.

\section{Discussion}

Complete preservation of the native mitral apparatus during MVR along with maintenance of the continuity between these structures and the mitral annulus has a beneficial effect on postoperative left ventricular performance. $^{1,2}$

A possible disadvantage of leaving the subvalvular apparatus intact during MVR is left ventricular outflow tract obstruction. ${ }^{3}$ There have also been reports of disc or poppet entrapment by surgically divided chordal remnants, long suture ends, overhanging knots, or atrial catheters. ${ }^{2}$ Rupture of a papillary muscle caused by hemorrhagic necrosis, with entrapment of the disc of the prosthetic valve (lethal complication), has been reported. ${ }^{4}$ Spontaneous rupture of a papillary muscle after chordal sparing MVR, seeking for a surgical solution to the problem, has also been noted. ${ }^{2,5}$

In our case we were faced with spontaneous tearing of the anterior mitral leaflet remnants. To the best of our knowledge, such a complication has not yet been reported. It was speculated that tearing of the leaflet remnants might have been caused by increased tension on preserved structures. We absolutely agree with the statement of Lemke and colleagues ${ }^{2}$ that every effort should be done to avoid tension on the subvalvular apparatus in chordal sparing MVR, especially when the chordal attachments to the valve leaflets are altered.

Being afraid of possible thrombosis, embolization, or poppet entrapments, we have urged redo surgery. In our opinion, when we are faced with similar problems, a limited approach throughout an aortotomy across the aortic valve simplifies the operation. 


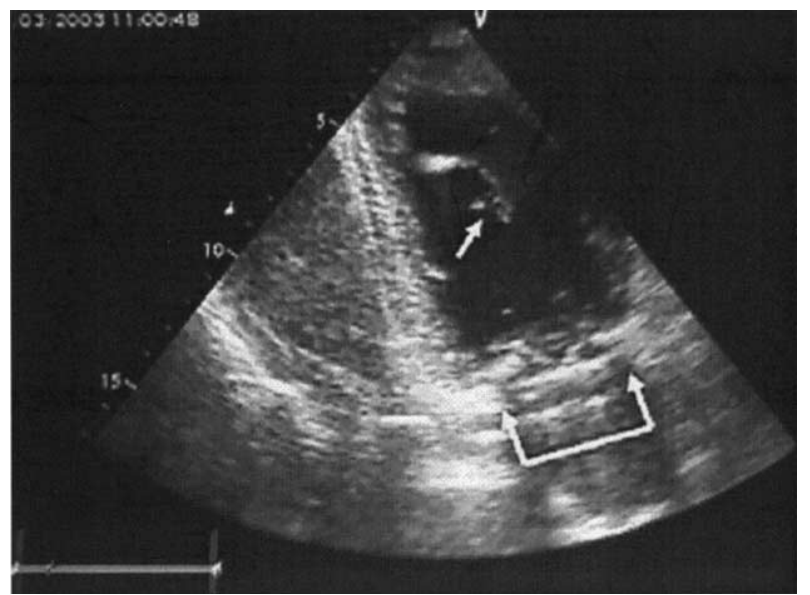

Figure 1. Transthoracic echocardiogram (apical, 2-chamber view) showing mitral prosthesis (double arrow) and structure (attached on posterior papillary muscle) floating in the left ventricular cavity (arrow).

\section{References}

1. Ohkita Y, Miki S, Ueda Y, Tahata T, Ogino H, Sakai T, et al. Mid-term results of mitral valve replacement combined with chordae tendineae replacement in patients with mitral stenosis. J Heart Valve Dis. 1997; 6:37-42.

2. Lemke P, Roth M, Kraus B, Hohe S, Klövekorn W, Bauer E. Ruptured papillary muscle after mitral valve replacement with preservation of chordae tendineae. Ann Thorac Surg. 2001;72:1384-6.

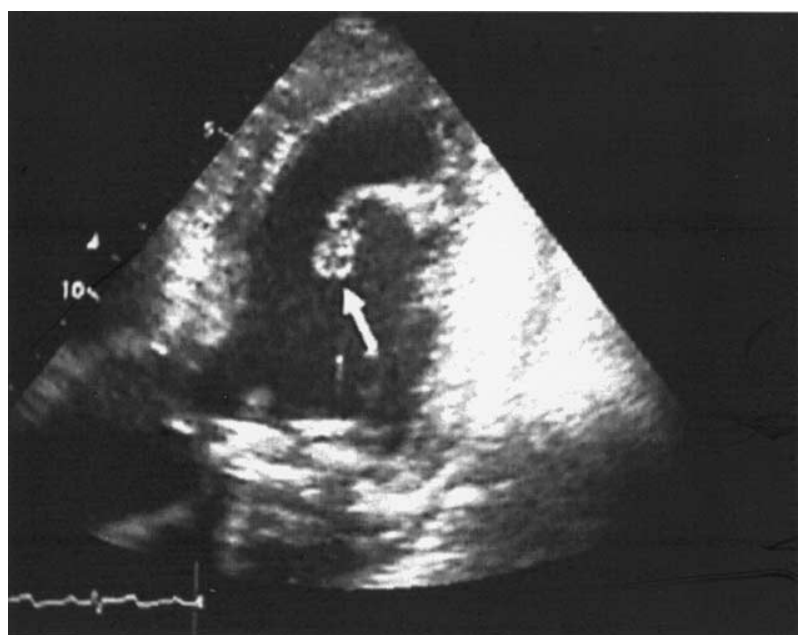

Figure 2. Transthoracic echocardiogram (apical, 4-chamber view) showing the torn remnant of the spared anterior leaflet still attached to the posterior papillary muscle (arrow).

3. Rietman GW, van der Maatan JM, Douglas YL, Boonstra PW. Echocardiographic diagnosis of left ventricular outflow tract obstruction after mitral valve replacement with subvalvular preservation. Eur J Cardiothorac Surg. 2002;22:825-7.

4. Mok CK, Cheung DL, Chiu CS, Aung-Khin M. An unusual lethal complication of preservation of chordae tendineae in mitral valve replacement. J Thorac Cardiovasc Surg. 1988;95(3):534-6.

5. Goldenberg MR, Rozanski LT, Degeratu FT, Berger BC. Papillary muscle rupture after chordal sparing mitral valve replacement. J Heart Valve Dis. 1998;7:590-2.

\section{Aortic dissection without Marfan's syndrome in ankylosing spondylitis}

Hisato Takagi, MD, PhD, Takayoshi Kato, MD, Yukihiro Matsuno, MD, PhD, Yukio Umeda, MD, PhD, Yukiomi Fukumoto, MD, PhD, Yoshio Mori, MD, PhD, and Hajime Hirose, MD, PhD, Gifu, Japan

\footnotetext{
From the First Department of Surgery, Gifu University School of Medicine, Gifu, Japan.

Received for publication Sept 28, 2003; accepted for publication Oct 2, 2003.

Address for reprints: Hisato Takagi, MD, PhD, First Department of Surgery, Gifu University School of Medicine, 40 Tsukasa, Gifu 500-8705, Japan (E-mail: h-takagi@cc.gifu-u.ac.jp).

J Thorac Cardiovasc Surg 2004;127:600-2

$0022-5223 / \$ 30.00$

Copyright $\odot 2004$ by The American Association for Thoracic Surgery doi:10.1016/j.jtcvs.2003.10.018
}

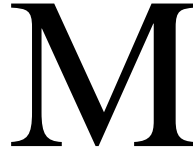

utations in the gene for fibrillin-1 (FBN1), which cause Marfan's syndrome, have been found not only in Marfan's syndrome but also in a range of connective tissue disorders collectively termed "fibrillinopathies," such as isolated ascending aortic aneurysm and dissection, ${ }^{1,2}$ isolated skeletal features, predominant skeletal manifestations without aortic dilatation, isolated ectopia lentis, and other variants. On the other hand, Simkin ${ }^{3}$ has hypothesized that the defective fibrillin of Marfan microfibrils and the inflammationtargeted fibrillin of ankylosing spondylitis may each lead to comparable structural phenotypes of failure. Two cases of coexistent ankylosing spondylitis and Marfan's syndrome without aortic dissection have been reported in the literature. ${ }^{4,5}$ To our knowledge, however, there have been no cases of aortic dissection in ankylosing spondylitis. Here we describe the first case of Stanford type A (DeBakey type I) acute aortic dissection without Marfan's syndrome in human leukocyte antigen (HLA)-B27-negative ankylos- 